\title{
Influence of Heat Treatment on Mechanical Properties of Aisi1040 Steel
}

\author{
Ashish Verma ${ }^{\mathrm{a}}$, Pravin Kumar Singh ${ }^{\mathrm{b}}$ \\ a. University Institute of Technology, Barkatullah University, Bhopal-462026 \\ b. University Institute of Technology, Barkatullah University, Bhopal-462026
}

\begin{abstract}
This investigation is concerned to evaluate the influence of heat treatment on mechanical behavior of AISII040 steel; it is one of the grades of medium carbon steel of American standard containing $0.40 \%$ carbon in its composition. Specimen of quenched/hardened AISI1040 steel was tempered at temperature $\left(650,450 \& 250^{\circ} \mathrm{C}\right)$ for $60,90 \& 120$ minutes to modify desired properties. The mechanical behavior, particularly, ultimate tensile strength, yield strength and elongation were investigated using universal testing machine; while the hardness measurement was done on Rockwell hardness testing machine of heat treated specimens. Result shows that the ultimate tensile strength and the yield strength decrease while the elongation increases with an increase in tempering temperature and tempering time of different tempered specimen. The hardness of quenched/hardened specimen decreases with an increase in tempering temperature and tempering time. Furthermore, increasing temperature and lowering time produces approximately same result as decreasing temperature and increasing time.
\end{abstract}

\section{Introduction}

Steel is an alloy of iron with definite percentage of carbon ranging from $0.15-1.5 \%$. These plain carbon steels are classified on the basis of their carbon content, as their major alloying element is carbon [1]. Steels with carbon content varying from $0.30 \%$ to $0.60 \%$ are classified as medium carbon steel, while those with carbon content less than $0.30 \%$ are termed as low carbon steel [1]. The carbon content of high carbon steels usually ranges within $0.60-1.5 \%$. Steel is mainly an alloy of iron and carbon, where other elements are present in quantities too small to affect its properties [2]. The other alloying elements alloyed in plain-carbon steel are manganese, silicon and phosphorus [2]. Steel with low carbon content has the same properties as iron i.e. soft but easily formed. As carbon content rises, the metal becomes harder and stronger but less ductile [3]. Medium carbon steels are used for fabrication. In addition, machined parts such as bolts, turbine casing and concrete reinforcing bars are made of this class of carbon steel. Gears, wire rods, seamless tubing, hot-rolled/coldfinished bars and forging products are also some objects constructed from medium carbon steel [4]. Although the number of steel specifications runs into thousand, plain carbon steel accounts for more than $90 \%$ of the total steel output. The reason for its importance is that it is a tough, ductile and cheap material with reasonable casting, working and machining properties, and also amenable to simple heat treatments to produce a wide range of properties [5].

Heat treatment is a combination of controlled heating and cooling applied to a particular metal or alloy in the solid state in such ways so as to produce certain microstructure and desired mechanical properties (hardness, ultimate tensile strength, yield strength and elongation) [11]. Annealing, normalizing, hardening/quenching and tempering are the most important heat treatments often used to modify the microstructure and desired mechanical properties in steel [6]. Heat treatment process leads to change in phase microstructural and crystallographic changes in material [3]. The purpose of heat treating carbon steel is to obtain mechanical properties of steel usually ductility. The standard strengths of steels used in engineering purposes are prescribed from their yield strength [7]. Most of engineering calculations for structure are based on yield strength. The heat treatment develops hardness, softness and improves the mechanical properties such as ductility [8]. This process also helps to improve machining effect, and make them versatile [7]. Heat treatment is also used to increase the strength of materials and to relieve stresses induced in material after manufacturing, forging and welding [16]. Hardened/quenched specimen has the highest tensile strength and hardness with lowest ductility and impact strength when compared to other heat treated specimen [15]. Hardening/quenching is strongly recommended when the strength and hardness are the prime desired properties in design. Quenching in water resulted in higher tensile strength and hardness possibly due to the formation of martensite structure which is one of the strengthening phases of steel [15].

The steel developed by quenching followed by tempering process at a desired temperature has the highest ultimate tensile strength with excellent combination of impact strength, ductility and hardness which is very attractive for industrial use [9]. On the basis of above survey it is very much clear that heat treatment is not a new area in fact most of the researchers look at the process in general. But it has not been localized for an 
improvement in desired mechanical properties of this material i.e. AISI1040 steel which is used in fabrication industries for massive production. Hence there is need to carry out this work for the further enhancement of desired mechanical properties in material which in turn increases the durability and performance of components made by this material.

Present work deals with influence of heat treatment on mechanical properties of AISI1040 steel with the objective of improving its mechanical properties.

\subsection{Selection of Material}

\section{Experimental set-up and procedure}

Steel of grade AISI1040 is being chosen for investigation. It is one of the American standard specifications of the plain carbon steel having $0.40 \%$ carbon in its composition, so it is called medium carbon steel. The chemical composition of AISI1040 is given in the table below:

Table1. Chemical Composition of AISI1040

\begin{tabular}{|c|c|c|c|c|c|c|}
\hline $\mathrm{C}$ & $\mathrm{Mn}$ & $\mathrm{Si}$ & $\mathrm{P}$ & $\mathrm{S}$ & $\mathrm{Cr}$ & $\mathrm{Fe}$ \\
\hline 0.40 & 0.77 & 0.20 & 0.03 & 0.02 & 0.04 & Balance \\
\hline
\end{tabular}

\subsection{Specimen Preparation}

The specimens of following dimensions, as shown in figure 2.1, were then prepared for test using a standard format of ASTM for heat treatment.

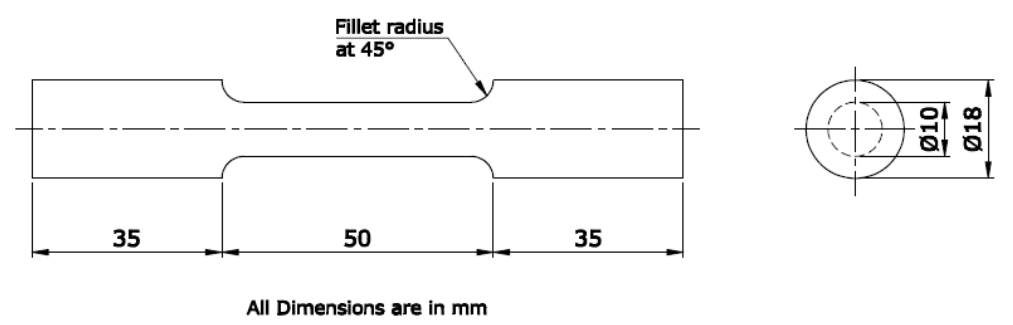

Fig. 2.1 Test specimen for AISI1040 steel

\subsection{Heat Treatment Processes}

After preparation, specimens were heated in muffle furnace at a temperature of $900^{\circ} \mathrm{C}$, and were held for 120minutes and then the specimens were quenched into water. After quenching the specimens were again heated for tempering, in this they were tempered at different temperature $\left(650,450 \& 250^{\circ} \mathrm{C}\right)$. At each temperature three specimens were heated but each was held for different tempering time i.e. first one for 60 minutes, second one for 90 minutes and third one for 120 minutes respectively.

\subsection{Mechanical Testing}

After successful heat treatment operations, the heat treated specimens were taken for the hardness and tensile test to determine the ultimate tensile strength, yield strength, elongation and hardness properties.

Hardness test was conducted on Rockwell hardness testing machine, while the tensile test was conducted on universal testing machine.

\section{Results and discussion}

The mechanical properties i.e. hardness, ultimate tensile strength, yield strength and elongation has been measured as a function of tempering temperature and tempering time. For every measurement, a specimen has been used which is quenched in water and tempered at different temperatures $\left(650,450\right.$ and $\left.250^{\circ} \mathrm{C}\right)$ for 60 , 90 and 120 minutes respectively. The results obtained from testing were described below:

\subsection{Hardness testing results}

The hardness property of tempered specimens is measured as function of tempering temperature and tempering time using Rockwell hardness tester. The results obtained from testing of specimens quenched at $900^{\circ} \mathrm{C}$ and tempered at temperature 650,450 and $250^{\circ} \mathrm{C}$ for different tempering time i.e. 60,90 and 120 minutes were shown in Fig. 3.1 and Fig. 3.2 respectively. 


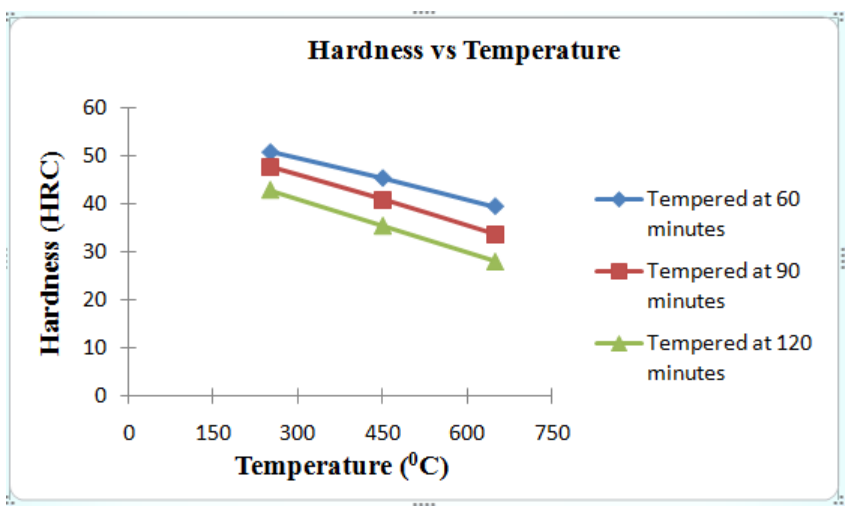

Fig. 3.1 Effect of tempering temperature on hardness of specimens tempered for different tempering time

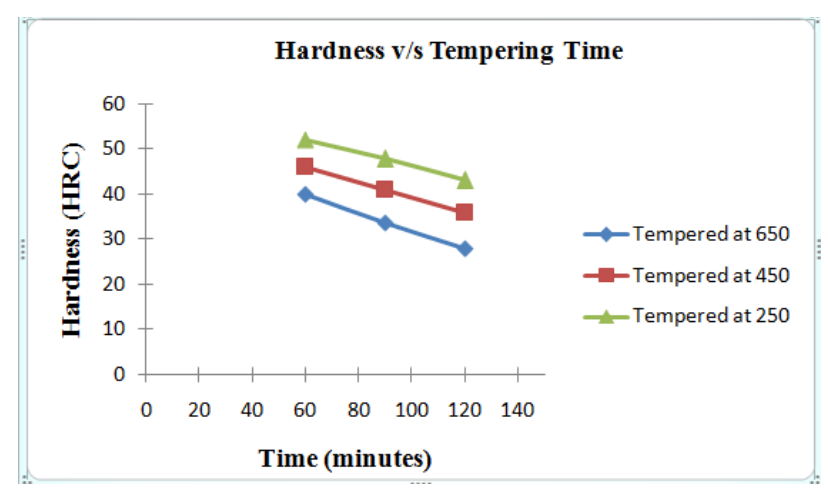

Fig. 3.2 Effect of tempering time on hardness of specimens tempered for different tempering temperature In relation with Fig. 3.1, in which hardness is plotted against tempering temperature and Fig. 3.2, in which hardness is plotted against tempering time; it has been seen that hardness of tempered specimen decreases with an increase in tempering temperature and tempering time. Furthermore, the results also indicate that the effect of tempering temperature is more significant than that of tempering time. The decrease in hardness with increasing temperature is due to the decomposition of the martensite and coagulation of carbides of the cementite which precipitate from martensite [11].

\subsection{Ultimate tensile strength testing results}

The ultimate tensile strength property of tempered specimens is measured as function of tempering temperature and tempering time using universal testing machine. The results obtained from testing of specimens quenched at $900^{\circ} \mathrm{C}$ and tempered at 650,450 and $250^{\circ} \mathrm{C}$ for different tempering time i.e. 60,90 and 120 minutes were shown in Fig. 3.3 and Fig. 3.4 respectively.

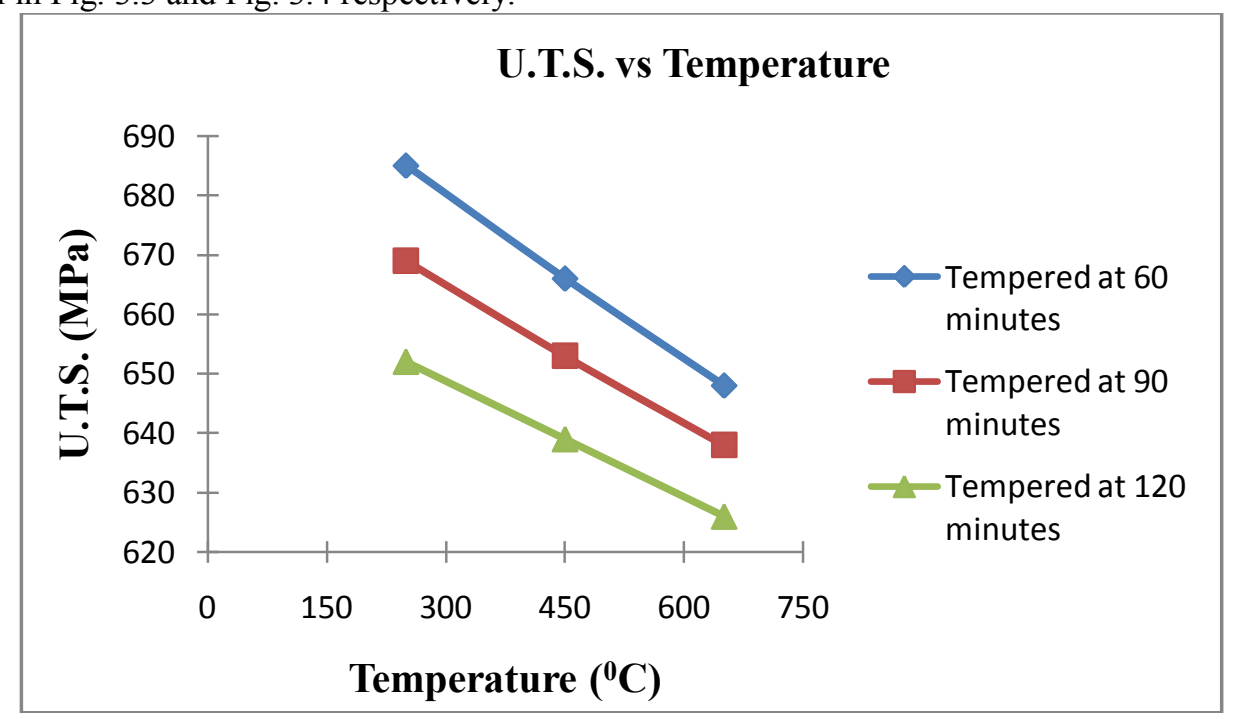

Fig. 3.3 Effect of tempering temperature on ultimate tensile strength for different tempering time 


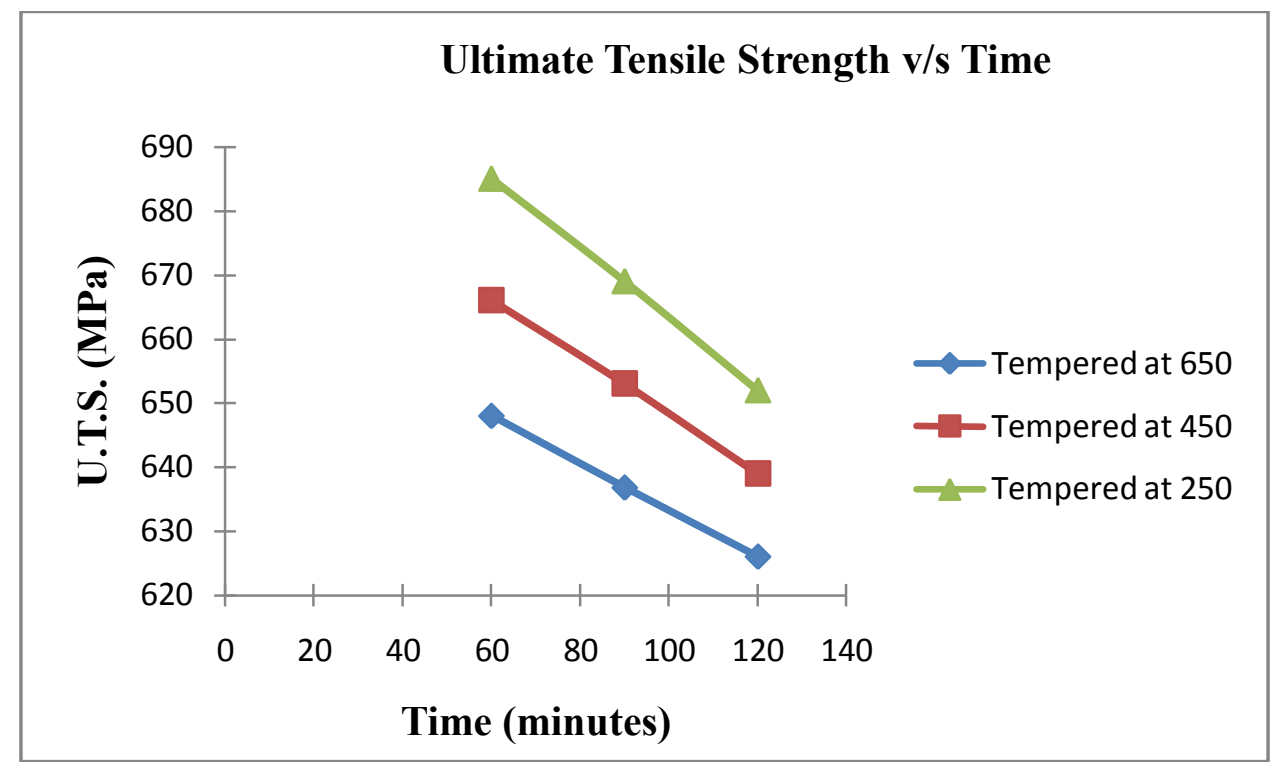

Fig. 3.4 Effect of tempering time on ultimate tensile strength for different tempering temperature

From the Fig. 3.3 in which ultimate tensile strength is plotted against tempering temperature for different tempering time of 60,90 and 120 minutes and the same is plotted against tempering time at different tempering temperature 650,450 and $250^{\circ} \mathrm{C}$ in Fig. 3.4. Both the figure shows that ultimate tensile strength of tempered specimen decreases with an increase in tempering temperature and tempering time. This can be explained by the fact that with an increase in tempering temperature carbon concentration of the matrix present in tempered martensite decreases due to the diffusion of carbon atoms to the cementite which leads to decrease in its ultimate tensile strength. Furthermore, ultimate tensile strength of quenched specimens tempered at $250^{\circ} \mathrm{C}$ for 90 minutes shows the same relationship as obtained by other investigators [19].

$\sigma_{\text {UTS }}(\mathrm{MPa})=859-0.75 \mathrm{~T}_{\text {tempering }}\left({ }^{\circ} \mathrm{C}\right) \ldots \ldots$ (1)

\subsection{Yield strength testing results}

The yield strength property of tempered specimens is measured as function of tempering temperature and tempering time using universal testing machine. The results obtained from testing of specimens quenched at $900^{\circ} \mathrm{C}$ and tempered at 650,450 and $250^{\circ} \mathrm{C}$ for different tempering time i.e. 60,90 and 120 minutes were shown in Fig. 3.5 and Fig. 3.6 respectively.

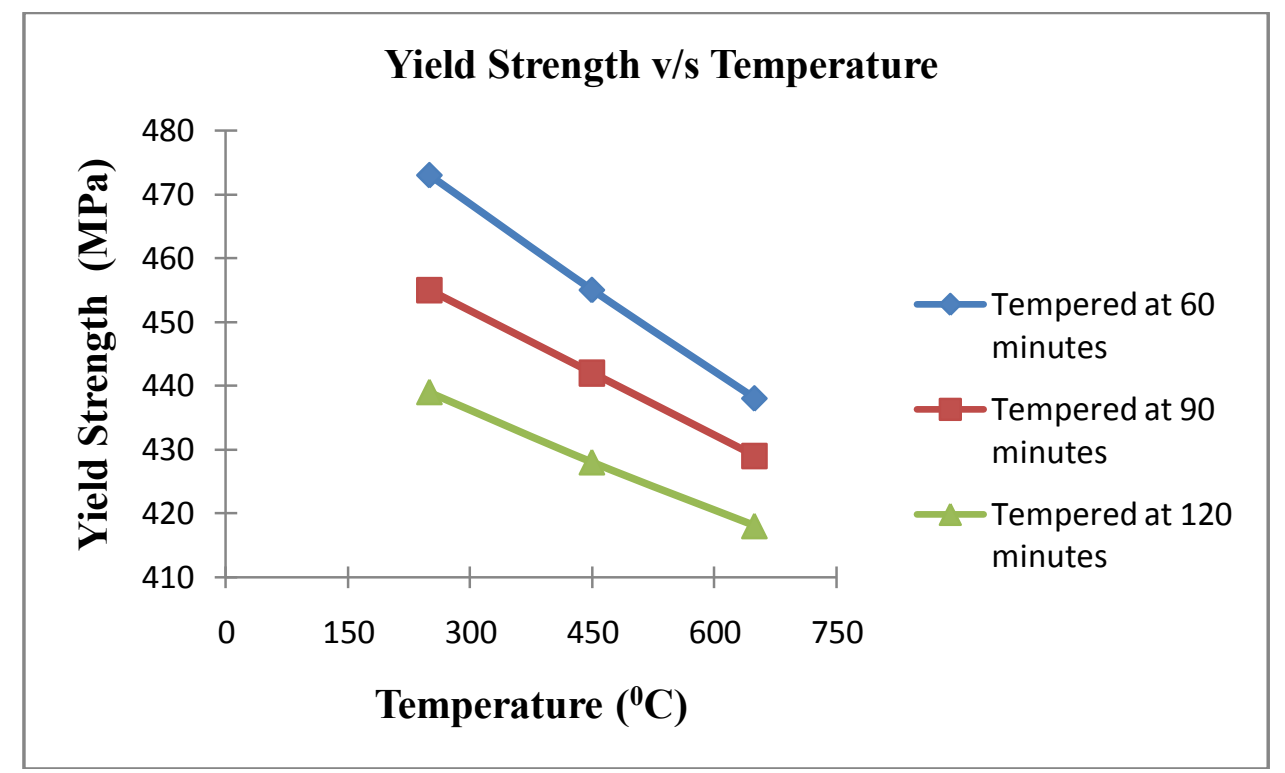

Fig. 3.5 Effect of tempering temperature on yield strength for different tempering time 


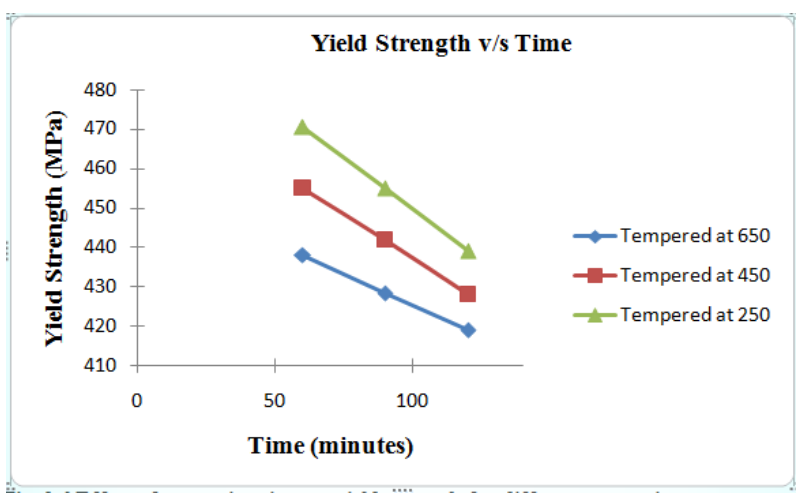

Fig. 3.6 Effect of tempering time on yield strength for different tempering temperature

The Fig. 3.5, in which yield strength is plotted against tempering temperature for different tempering time and Fig. 3.6 in which yield strength is plotted against tempering time for different tempering temperature shows that yield strength of tempered specimen decreases with an increase in tempering temperature and tempering time because of dual phase strengthening mechanics which results in grain re-arrangement due to subsequent increase in tempering temperature and time. However, it also indicates that the effect of tempering temperature is more significant than that of tempering time.

\subsection{Elongation testing results}

The elongation property of tempered specimens is measured as function of tempering temperature and tempering time using universal testing machine. The results obtained from testing of specimens quenched at $900^{\circ} \mathrm{C}$ and tempered at 650,450 and $250^{\circ} \mathrm{C}$ for different tempering time i.e. 60,90 and 120 minutes were shown in Fig. 3.7 and Fig. 3.8.

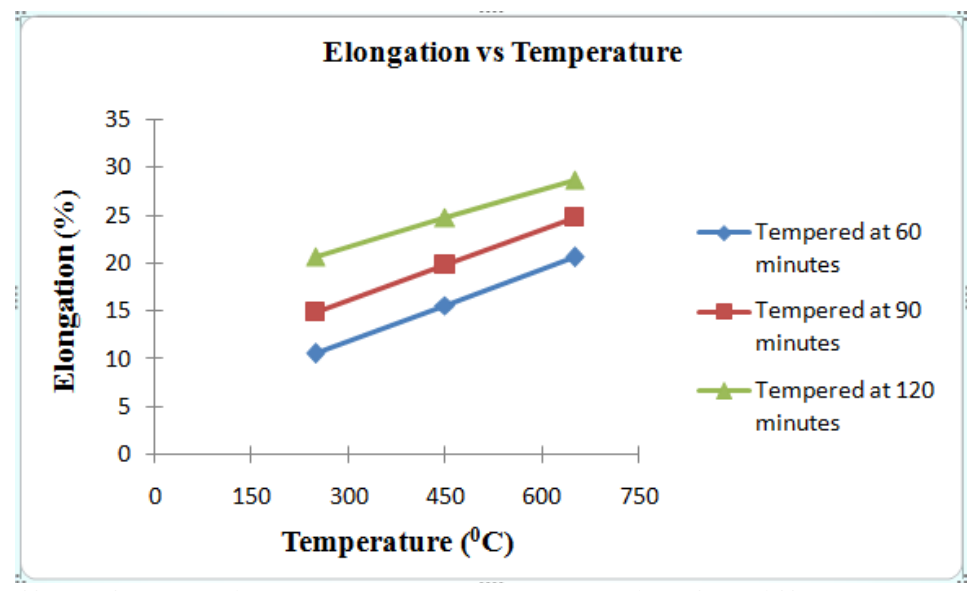

Fig. 3.7 Effect of tempering temperature on elongation for different tempering time

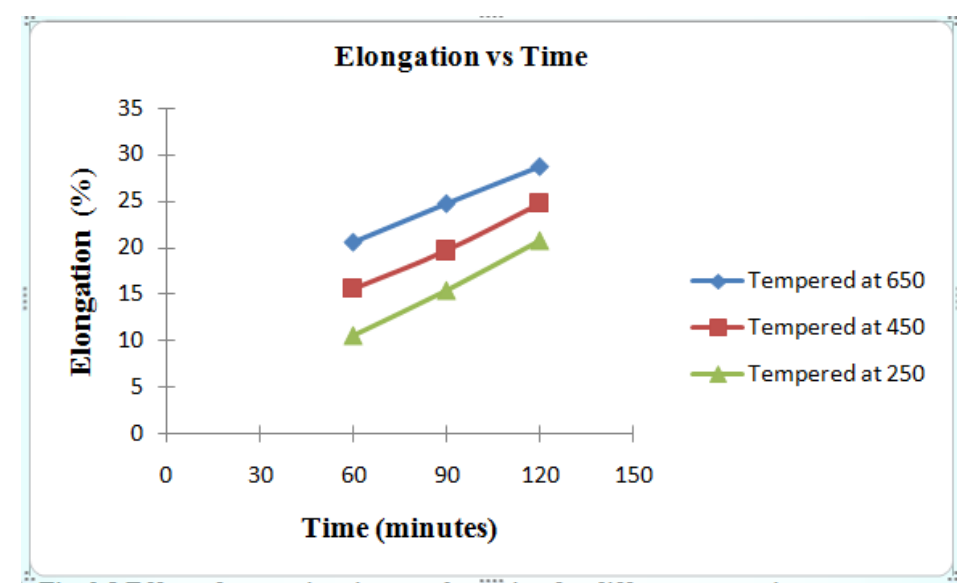

Fig. 3.8 Effect of tempering time on elongation for different tempering temperature 
The above mentioned figure i.e. Fig. 3.7 and Fig. 3.8 in which elongation is plotted against tempering temperature and tempering time respectively. It has revels that elongation of tempered specimen increases with an increase in tempering temperature and tempering time. This can be explained on the basis of established theory that with an increase in tempering temperature the concentration of carbon content in tempered martensite decreases continuously due to diffusion of carbon atom in cementite and also the formation of microstructure of ferrite and pearlite leads to induce ductility in specimen.

\subsection{Discussion}

As expected that mechanical behaviour of medium carbon steel i.e. AISI1040 steel is quite sensitive to tempering temperature and tempering time [11]. AISI1040 steel has a microstructure of ferrite and pearlite.

Under quenched condition when specimens are heated at a temperature $900^{\circ} \mathrm{C}$, held for two hour at that temperature than quenched rapidly in water at that time phase transformation of steel takes place, where the lattice structure of steel changes immediately from a face centered cubic $(\gamma-$ phase $)$ to body centered tetragonal martensite [15]. Furthermore, large amount of distortion occured during the formation of platelets of martensite, which in turn leads to rapid increase in its hardness [18]. The hardness of steel increases rapidly as the martensite percentage is increased because it is one of the most common strengthening phases in steel [1]. In general, the microhardness increases because of the refinement of the primary phases after rapid cooling [16]. It is well known that the water quenching creates a supersaturated solid solution and increase vacancies with carbon content in quenched specimens. Thus high hardness correlates with high resistance to slip and dislocation. In martensite, the carbon dependence of hardness is attributed to carbon atoms trapped in the octahedral interstitial sites of martensitic crystal structure [17].

But martensite is also brittle, highly stressed, low ductility and unstable phase [1]. During quenching one more unstable phase has been obtained i.e. retained austenite. The resultant microstructure after quenching process are observed as martensite with small amount of retained austenite while after tempering process the resulting optimum mechanical properties are found at bainitic structure [11].

Heating hardened/quenched steel to a temperature below lower critical temperature is called tempering. Tempering reaction can be pictured as the change of carbon atom dispersed in the martensite to precipitated carbide particle of increasing size and involve processes, such as precipitation of carbides, decomposition of retained austenite and recrystallization of martensite structure.

As the temperature of hardened steel is raised for tempering the mobility of atoms increases and the phase tends to pass into a stable/equiliberium state. For this change to occur both temperature and time are variable but temperature is more important variable than time, because lowering temperature and increasing time can usually produces same results as increasing temperature and decreasing time. During tempering, martensite decomposes into a mixture of ferrite and cementite with a resultant decrease in volume of martensite platelets as tempering temperature increase which in turn leads to change in its physical and mechanical properties.

When the specimens are tempered at temperature $650^{\circ} \mathrm{C}$ the phase transformation takes place from an unstable martensite to a mixture of ferrite and cementite. At this temperature cementite $\left(\mathrm{Fe}_{3} \mathrm{C}\right)$ agglomerates and coalesces. The structure becomes an aggregate with ferrite and cementite in quite fine spheres, referred to as tempered martensite and tempered bainite. Further increase in tempering time and tempering temperature leads to develop sorbite structure, consist of ferrite and finely divided cementite which imparts high ductility and low hardness.

The microstructure of specimens tempered at $650^{\circ} \mathrm{C}$ consists of equiaxed grain of ferrite and small rod shaped carbides that distribute within the ferrite matrix in specific direction. Also the dislocation cell boundaries and random dislocations situated between these cells disappear, whilst a fine cellular structure is developed when tempered at $650^{\circ} \mathrm{C}$ for 120 minutes [18].

When the specimens are tempered at temperature $450^{\circ} \mathrm{C}$, phase transformation takes place from retained austenite to bainite. Bainitic structure consist of ferrite and epsilon carbide which are formed at temperature ranging between $400^{\circ} \mathrm{C}-450^{\circ} \mathrm{C}$ for each tempering time while maximum elastic properties has been developed during one hour tempering treatment. Also cementite precipitate and ferrite matrix are found in range $500^{\circ} \mathrm{C}-550^{\circ} \mathrm{C}$ [12]. Furthermore, low carbon martensite changes to cubic ferrite and develop toorsite structure, which consists of radial lamellae of ferrite and cementite differs from pearlite only in degree of fineness and carbon content [15]. At this temperature a mixture of ductility and hardness is found but also temper brittleness i.e. notch impact intergranular brittleness is observed by researchers at this temperature with increasing time [11].

Also at this temperature a sudden drop in hardness and tensile strength is observed while yield strength has also decreased rapidly. But elongation in specimens has been observed which shows that they have gain ductility with loss of hardness. Furthermore, material has also observed some brittleness at this temperature which may be due to the presence of temper brittleness. 
Also at a temperature $250^{\circ} \mathrm{C}$, a hexagonal close packed carbide (epsilon carbide) begin to form i.e. precipitation epsilon carbide due to decrease of tetragonality of martensite and decomposition of retained austenite which leads to formation of rod or plates of cementite with complete loss of tetragonality of martensite and dissolution of epsilon carbide [11], with this rejection of carbon the crystal structure martensite changes ultimately from tetragonal to the body centered cubic characteristics of ferrite. Now with the increase in tempering time at tempering temperature $250^{\circ} \mathrm{C}$ retained interlath austenite and carbide films that are decomposed from the lath boundary retained austenite are formed. Furthermore, dendritic carbide $\left(\mathrm{Fe}_{3} \mathrm{C}\right.$, orthorhombic) forms and its initial morphology in martensite is platelike. The nucleated site of the carbide is frequently martensite lath boundaries at low temperature, and ferrite grain boundaries at higher temperature [18]. As the tempering temperature increases to $350^{\circ} \mathrm{C}$ the epsilon iron carbide is replaced by cementite and the martensite loses its tetragonality. The matrix structure of the tempered martensite transforms to body centre cubic (B.C.C.) and the carbon concentration of the matrix approaches that of ferrite. Furthermore, when the tempering temperature is higher than $350^{\circ} \mathrm{C}$ the cementite in the tempered martensite coarsens and spheroidises thus the strength difference between the ferrite and the tempered martensite is reduced which in turn leads to decrease in ultimate tensile strength and increases the elongation [12]. With an increase in the tempering temperature the carbon concentration of the matrix in the tempered martensite still decreases due to the diffusion of carbon atoms into cementite therefore, the strength and hardness of the tempered specimen decreases and its ductility increases.

\section{Conclusion}

1. The results show that the ultimate tensile strength and to some extent the yield strength decrease, whereas the elongation increases with increase in tempering temperature and tempering time.

2. For a given tempering time, the ultimate tensile strength and the yield strength decrease, whereas the elongation and hence the ductility i.e. elongation increases by increasing the tempering temperature.

3. Ultimate tensile strength decreases continuously by increasing tempering temperature and time. The ductility of the specimen is measured by the tensile test. The elongation increases with the increase in tempering temperature and time.

4. The higher is the tempering temperature, the lower is the hardness or the more is softness (ductility) induced in the previously quenched specimen.

5. The longer is the tempering time (keeping the temperature constant), the higher is the ductility induced in the specimen as a result of the grain re-arrangement.

\section{References}

[1] Rajan, T.V. Sharma, C.P Sharma, "Heat treatment - Principles and Techniques", Prentice- Hall of India Private Limited, New Delhi, India, pp36-42, 1988 .

[2] Oberg, E; et al., "Machinery’s Hand book" (25thed.) Industrial Press Inc, 1996.

[3] Smith, W.F. and Hashemi, J., "Foundations of materials science and Engineering”, 4thEdition; McGraw's- Hill Book.pp.28-36, 2006.

[4] Jacob Klinginsmith, Russ Glass, and Naomi Sanders, Becky Moffitt, "The Science and Engineering of Materials“(Fourth Edition): Donald R. Askland and Pradeep P. Phule: Brooks/Cole copyright 2003.

[5] Dell, K.A., "Metallurgy Theory and practical Text book ", American Technical Society, Chicago, pp.351-353, [6] Raymond A., Higgins B., "Properties of Engineering Materials", Hooder and Stonghton,

[7] Rao P.N, "Manufacturing Technology", Vol.1, the McGraw Hill Companies -New Delhi, pp.11-53, 2011.

[8] Adnan calik, Effect of cooling rate on Hardness and Micro structure of AISI 1020, AISI 1040 and AISI 1060 steels, Int .J. of Physics Sciences, Vol. 4(9), pp. 514-518, 2009.

[9] Daramola O.O Adewuyi B.O, Oladele I.O, Effects of Heat Treatment on the Mechanical Properties of Rolled Medium Carbon Steel, Journal of Minerals \& Materials Characterization \& Engineering, Vol.9, N0.8, pp.693-708, 2010

[10] Lakhtin.Y, Engineering Physical Metallurgy, MIR Publishers, Mascow, pp.14-55, 1998.

[11] Min Shan HTUN, Si Thu KYAW, Kay Thi LWIN, Effect of Heat Treatment on Microstructures and Mechanical Properties of Spring Steel, Journal of Metals, Materials and Minerals, Vol.18 No.2, pp.191-197, 2008 [12] X. Fang, Z. Fan, B. Ralph, P. Evans, R. Underhill, Effects of tempering temperature on tensile and hole expansion properties of a C-Mn steel, Journal of Materials Processing Technology, 132 (2003), 215-218

[13] Jamiu Kolawole odusote, Tajudeen Kolawole Ajuboye, Abdulkarim Baba Rabiu, Evaluation of mechanical properties of medium carbon steel quenched in water and oil, AU J.T.15 (14), pp 218-224, 2010.

[14] Ahmet Kaynar, Suleyman Gunduz, Mustafa Turkmen, Investigation on the behavior of medium carbon and vanadium micro alloyed steels by hot forging test, Materials and Design, Elsevier, 51 (2013), 819-825.

[15] O. P. Khanna, "Material Science and Metallurgy", Dhanpat Rai Publications (P) LTD, New Delhi, India, 110002, pp43-1 $43.51,2004$.

[16] Wang x, HMLU, XL Li, Zheng Yf, Microscopic phase field simulation coupled with elastic strain energy for precipitation process of Ni-Cr-Al alloy with low Al content, Trans. Nonferrous Met. Soc. China, 17:22, 2007

[17] Kurdjumov GV, Khachaturyan AG, Phenomena of carbon atom redistribution in martensite, Metallurgical and materials trans., B3,5, 1972 .

[18] Woei Shyan Lee, Tzay Tian Su, Mechanical properties and microstructural features of AISI4340 high strength alloy steel under quenched and temperedcondition, Journal of Materials Processing Technology,198-206, 1999

[19] S.S.M. Tavares, P.D. Pedroza, J.R. Teodosia, T. Gurova, Mechanical properties of a quenched and tempered dual phase steel, Scripta Mater. 40 (1999) 887-892. 